\title{
The Effects of Spark Training on Visual-Spatial Working Memory Operation in Children with Mental Retardation
}

\author{
Mahmoud Sheikh ${ }^{1 *}$, Shahin Ramezani ${ }^{1}$, Golaleh Maghsoudy ${ }^{2}$, Khaled Ahmadi² \\ ${ }^{1}$ Department of Motor Behavior, Faculty of Physical Education, Tehran University, Tehran, Iran \\ ${ }^{2}$ Exceptional Children's School, Orumiyeh, Iran
}

\section{ABSTRACT}

Introduction: Mental retarded children who receive a wide range of health services, representing more than two percent of the population. Mental retardation is associated with significant constraints on mental performance and adaptive behavior as well as perceptual and practical skills. According to the studies, one of the important tools that can affect cognitive abilities, such as memory, is physical activity. Due to the memory problems in children with mental retardation, this study aimed to investigate the effects of spark training on visual-spatial working memory operation in children suffering from mental retardation. Materials and Methods: The Study population included educable mentally retarded students in Urmia. 20 mentally retarded boys of age 9 to 12 years were selected and divided into two groups; experimental and control. Spark programs that includes strengthening activities as well as games and sports for children were performed for 18 sessions on the experimental group. Corsi Blocks test was used to collect the visual-spatial memory data. Results: The results showed a significant difference in the visual-spatial work memory score between the experimental and control groups. Conclusion: Spark exercises can improve the performance of the visual-spatial work memory of trained mentally retarded children.

Key words:

1. Child

2. Exercise

3. Memory, Short-Term

*Corresponding Author: Mahmoud Sheikh

E-mail:prosheikh@yahoo.com 


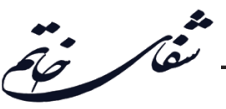

تأثير تمرينات اسيارك بر عملكرد حافظةٌ كارى ديدارى -فضايى كودكان مبتلا به كمتوانى ذهنى

\author{
محمود شيخ '،: شهين رمضانى'، گَلاله مقصودى'، خالد احمدى' \\ اكروه رفتار حركتى، دانشكده تربيت بدنى، دانشعاه تهران، تهران، ايران \\ rمدرسه كودكان استثنايى، اروميه، ايران
}

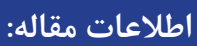

كليد وازهها:

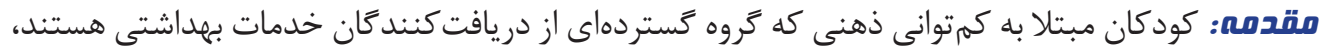

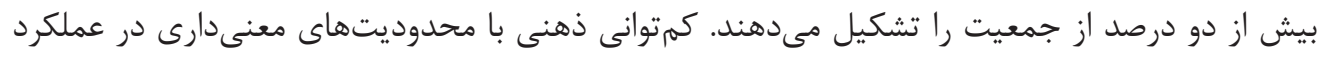

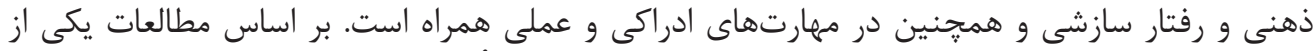

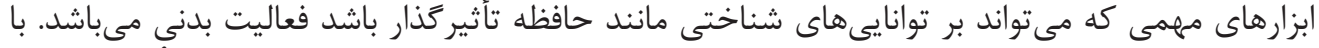

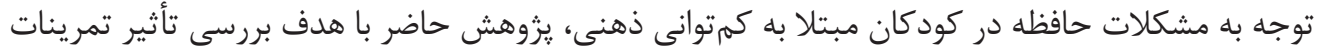

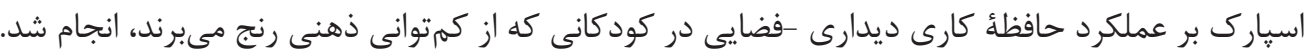

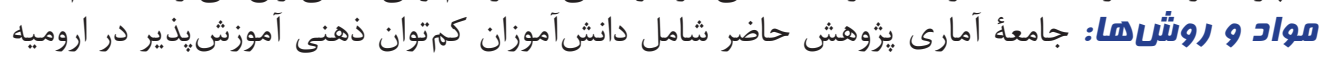

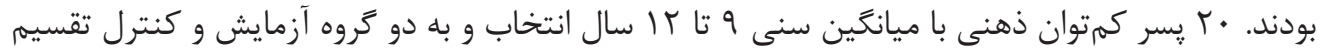

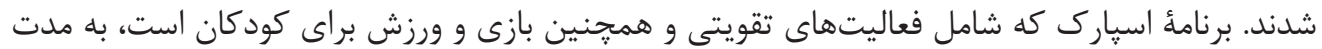

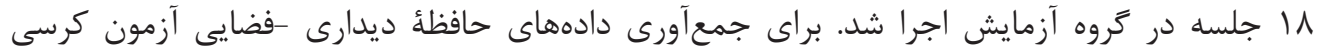

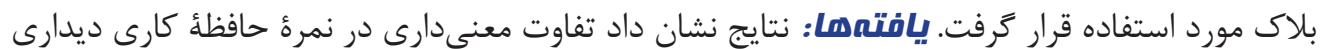

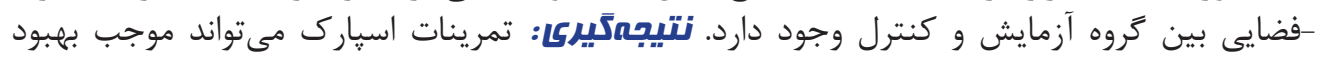

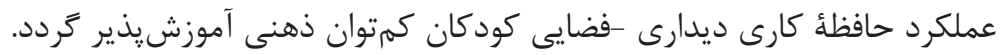


شـده بــه وسـيلئه مكانيسـمهاى توجــهـ اسـت كـهـ اطلاعـات

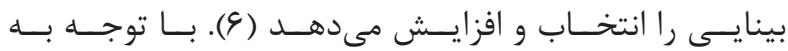

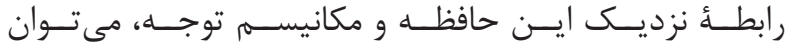

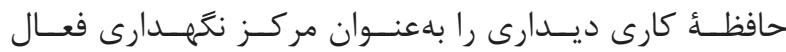

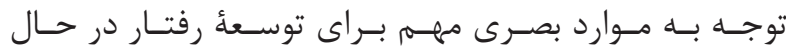

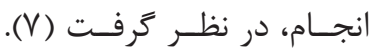

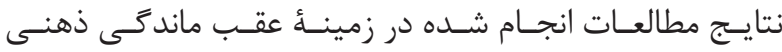

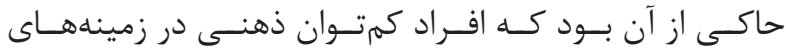

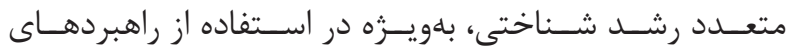

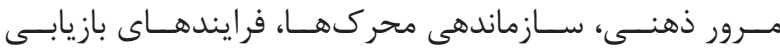

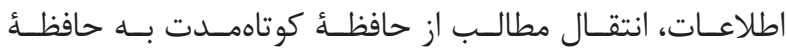

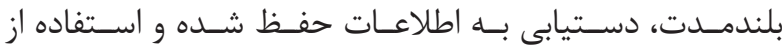

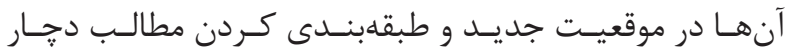

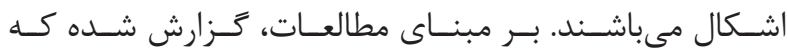

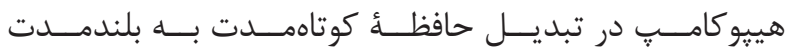

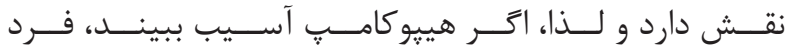

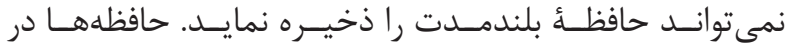

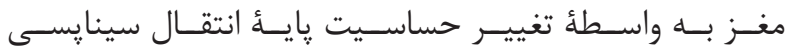

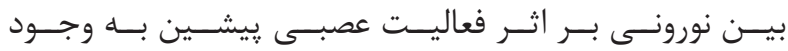

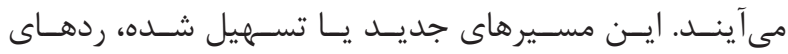

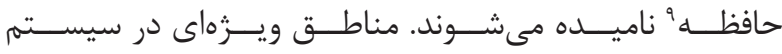

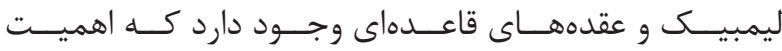

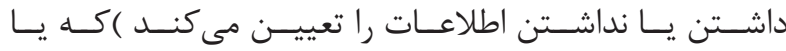

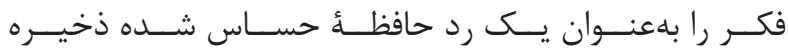

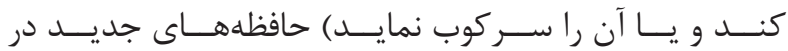

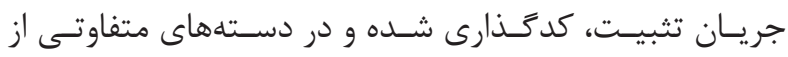

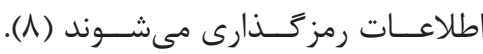

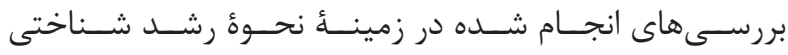

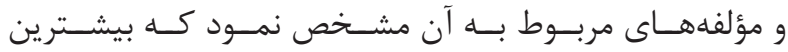

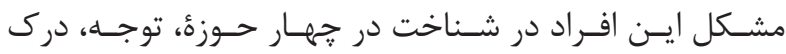

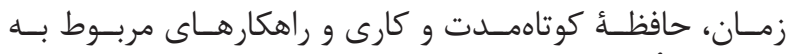

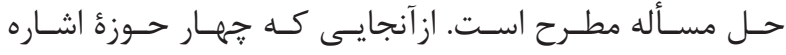

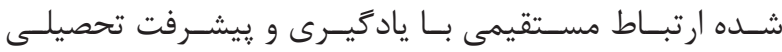

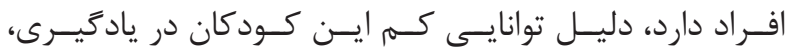

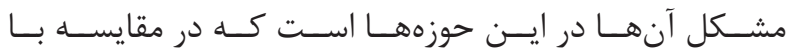

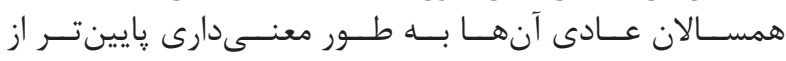

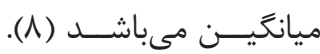

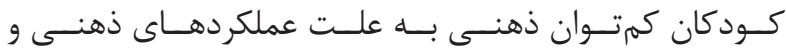

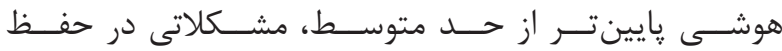

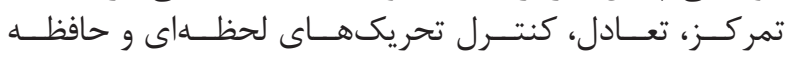

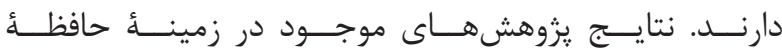

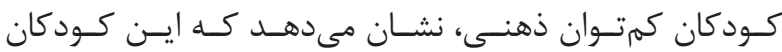

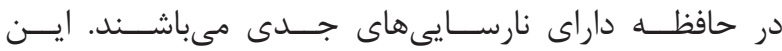

${ }^{1}$ Mental retardation

${ }^{2}$ Adaptive behaviors

${ }^{3}$ Working memory

${ }^{4}$ Baddeley

${ }^{5}$ Central executive

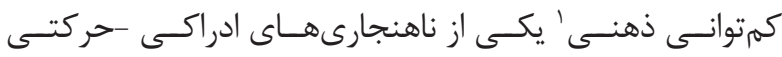

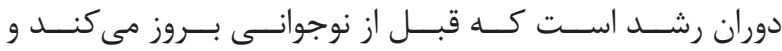

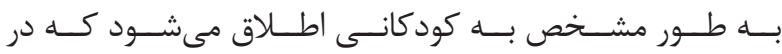

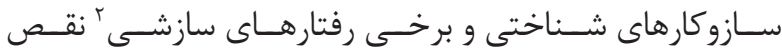

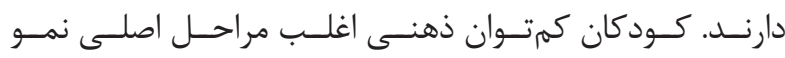

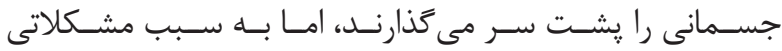

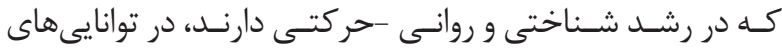

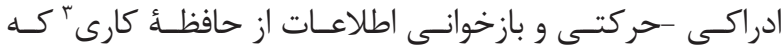

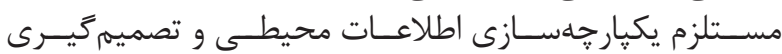

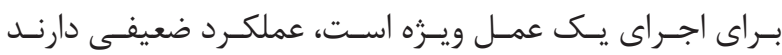

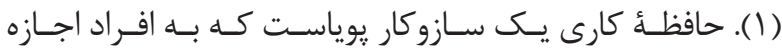

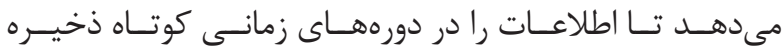

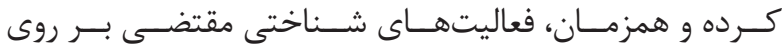

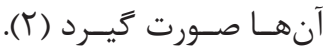

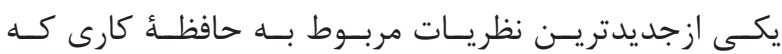

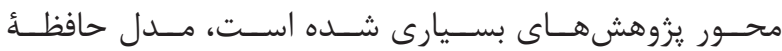

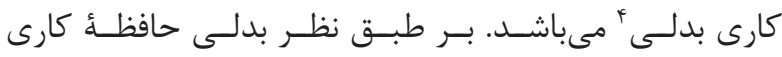

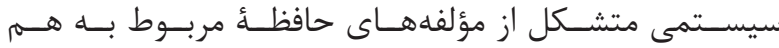

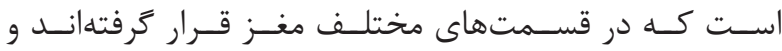

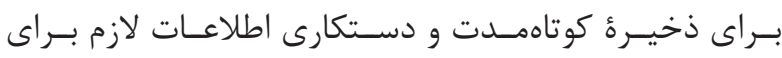

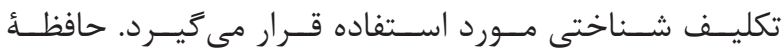

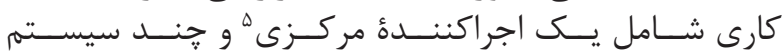

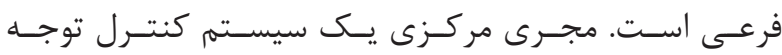

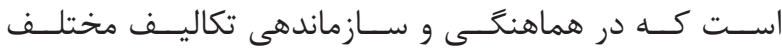

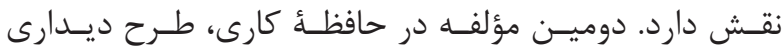

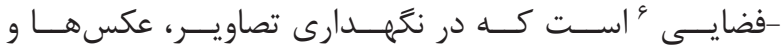

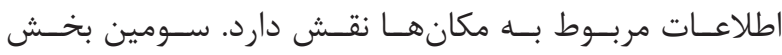

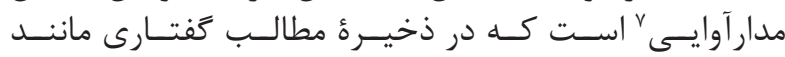

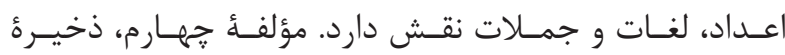

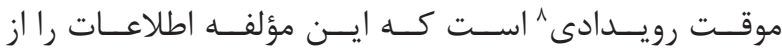

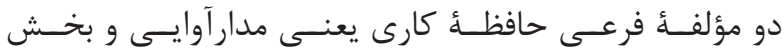

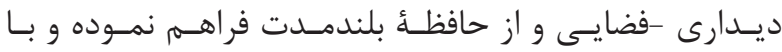

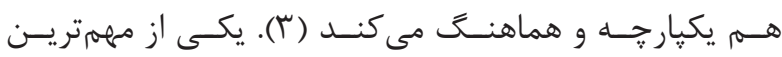

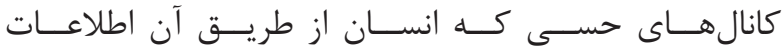

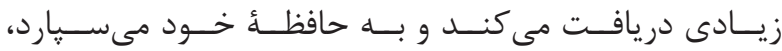

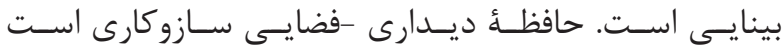

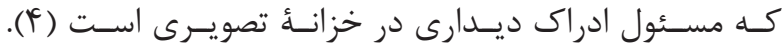

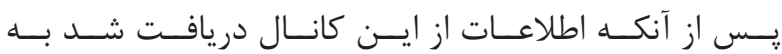

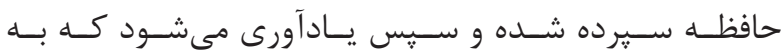

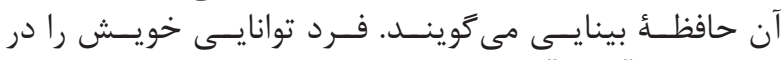

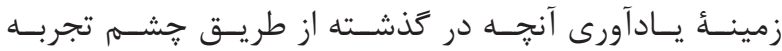

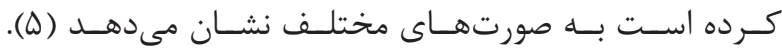

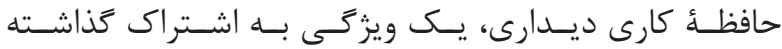

${ }^{6}$ Visuo spatial sketchpad

${ }^{7}$ Phonological loop

${ }^{8}$ Visual-manual dexterity

${ }^{9}$ Memory tracce 


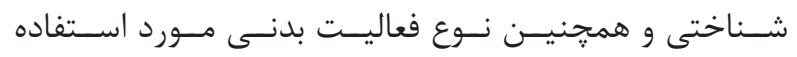

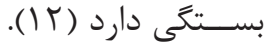

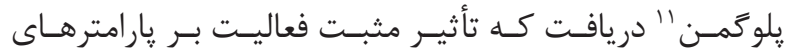

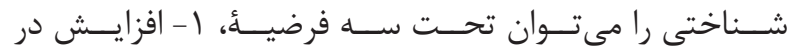

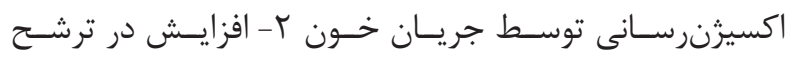

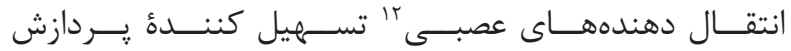

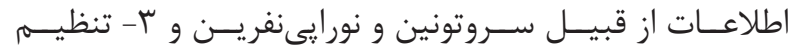

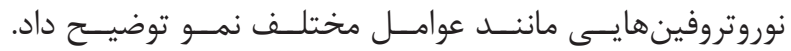

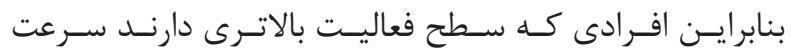

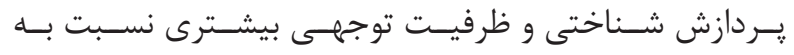

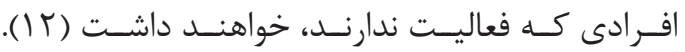

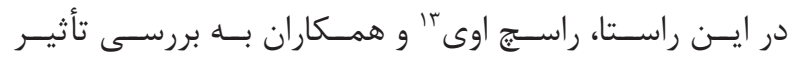

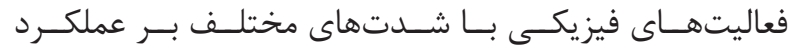

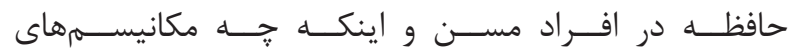

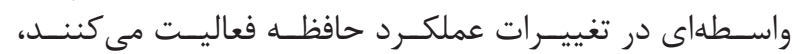

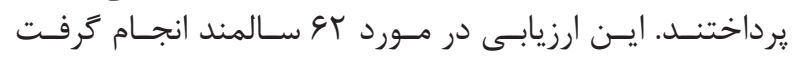

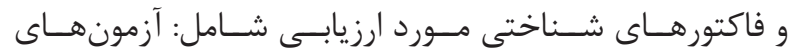

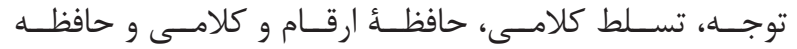

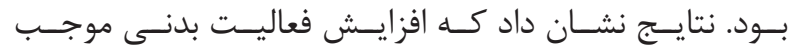

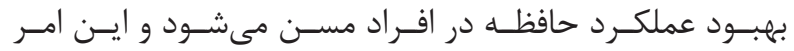

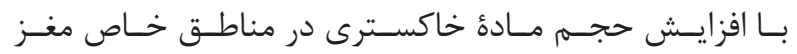

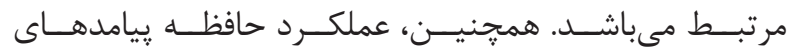

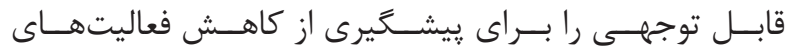

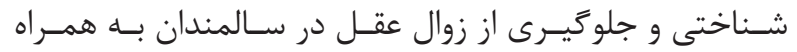

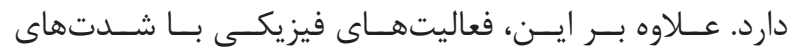

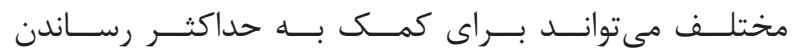

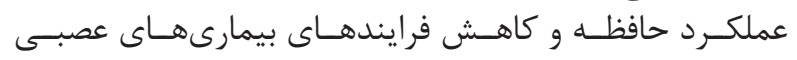

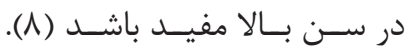

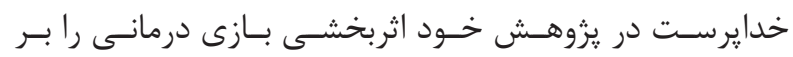

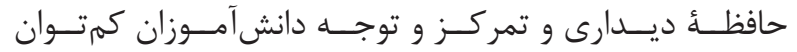

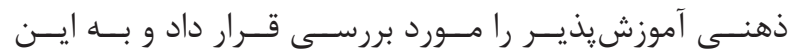

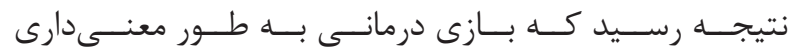

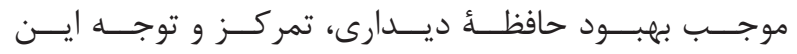

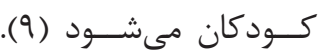

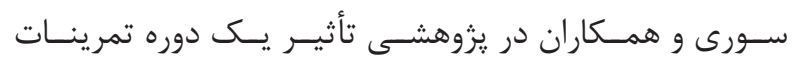

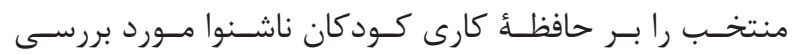

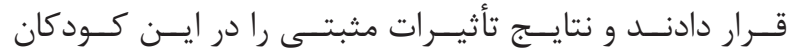

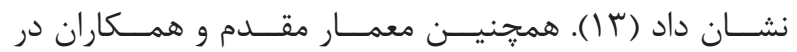

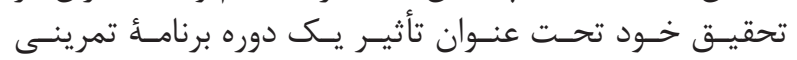

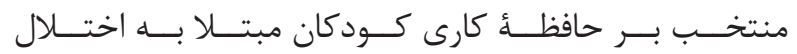

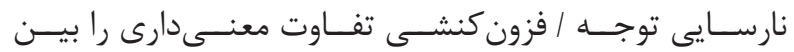

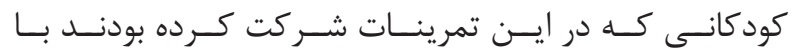

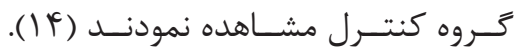

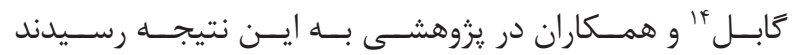

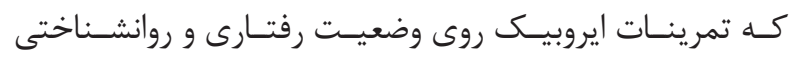

${ }^{10}$ Neutrophic

${ }^{11}$ Ploughman

${ }^{12}$ Neurotransmitters

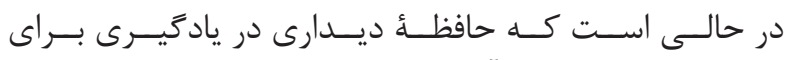

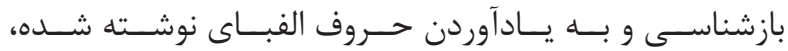

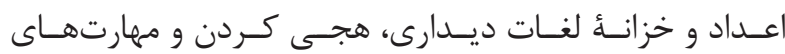

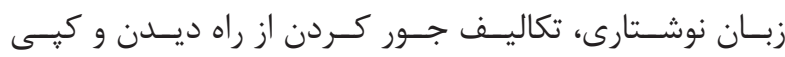

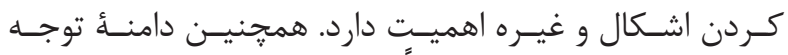

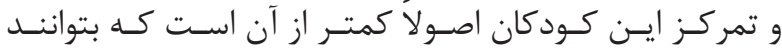

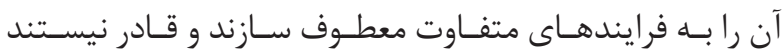

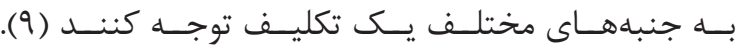

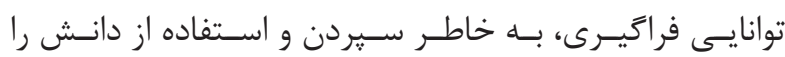

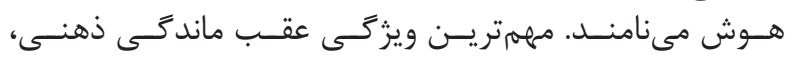

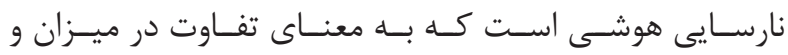

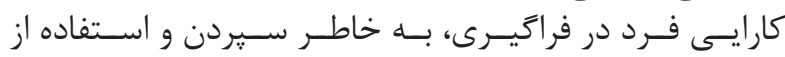

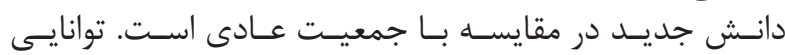

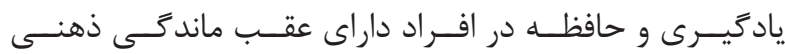

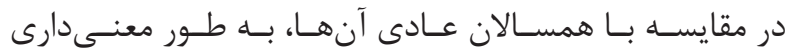

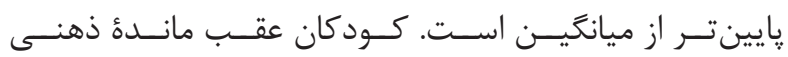

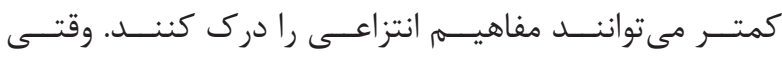

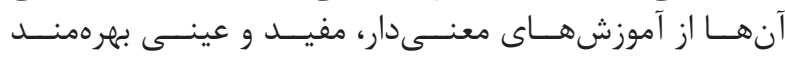

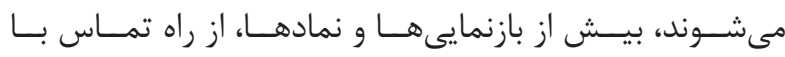

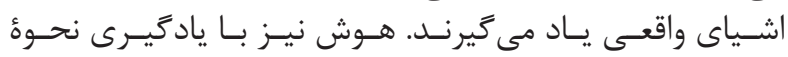

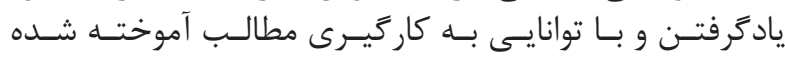

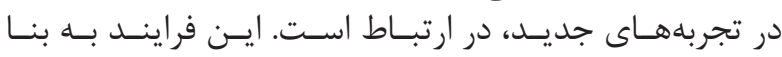

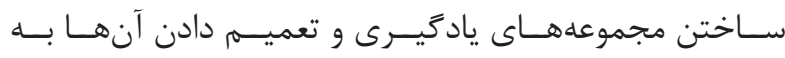

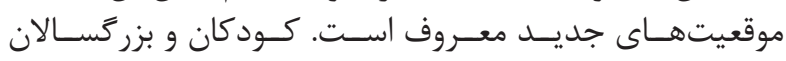

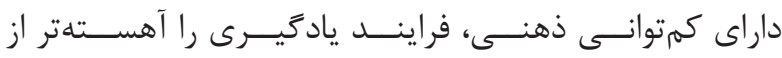

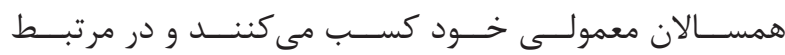

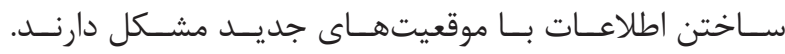

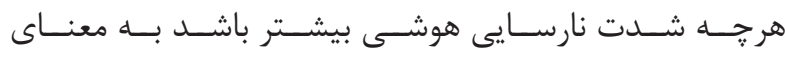

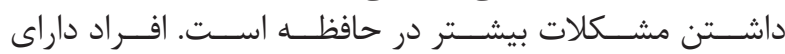

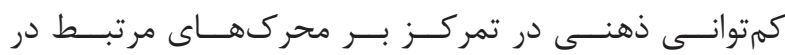

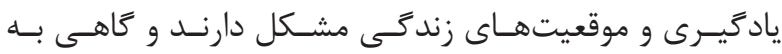

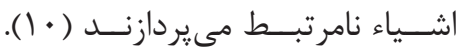

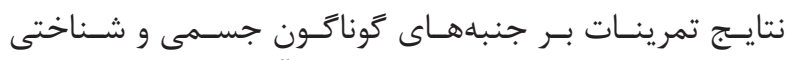

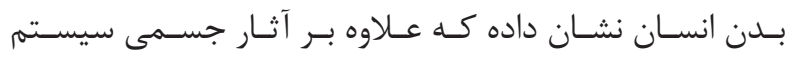

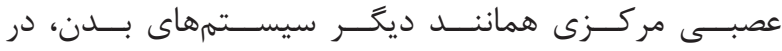

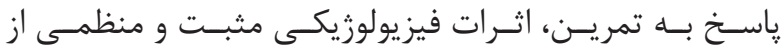

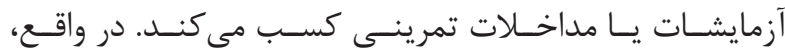

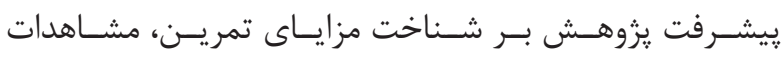

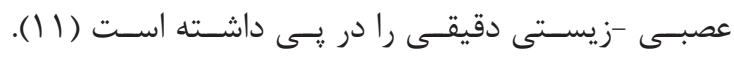

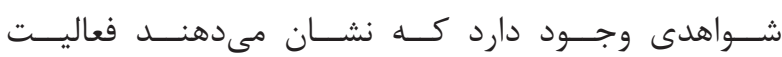

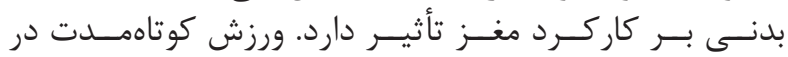

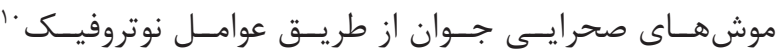

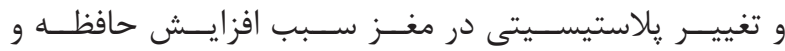

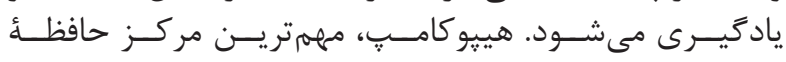

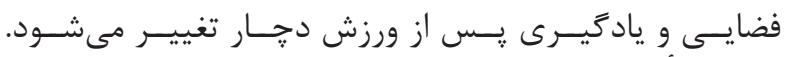

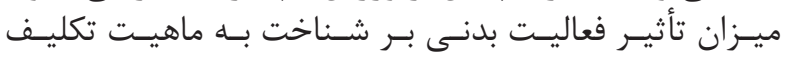

\section{${ }^{13}$ Ruscheweyh}

${ }^{14}$ Gable 


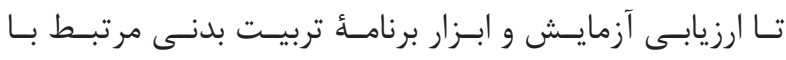

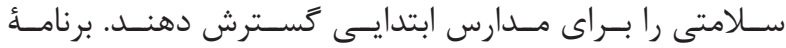

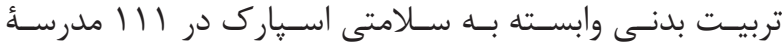

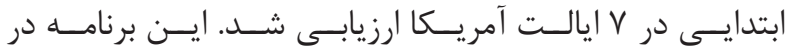

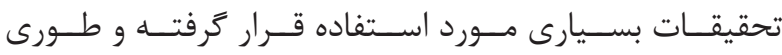

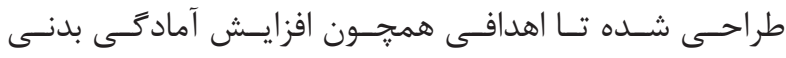

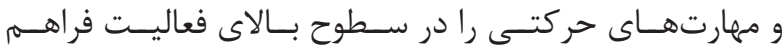

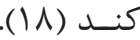

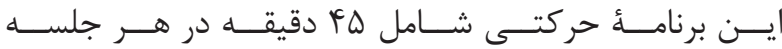

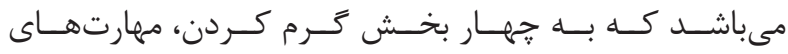

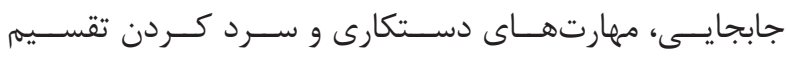

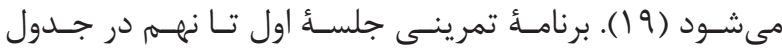

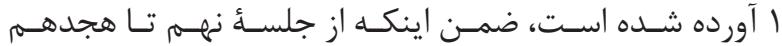

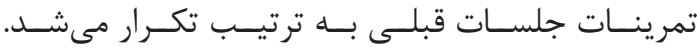

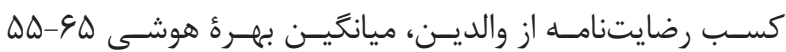

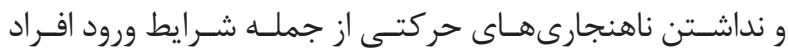

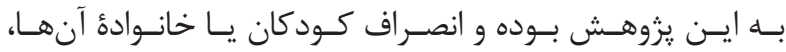

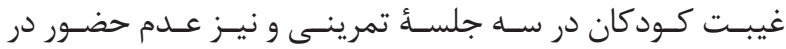

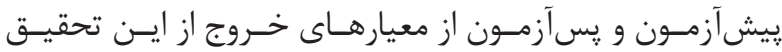

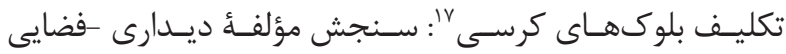

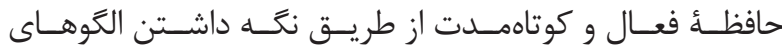

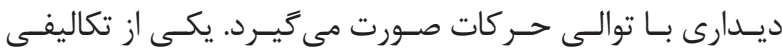

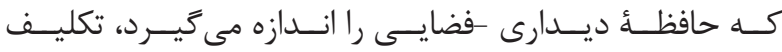

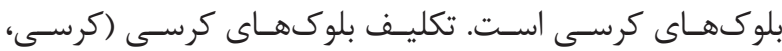

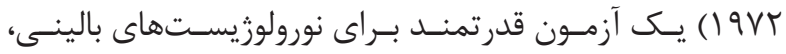

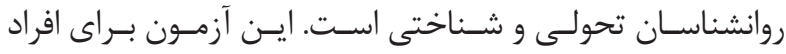

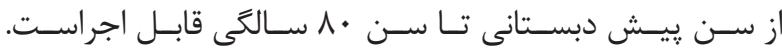

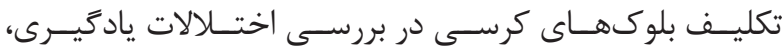

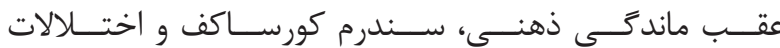

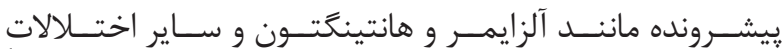

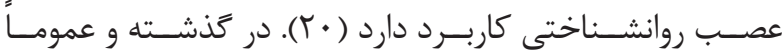

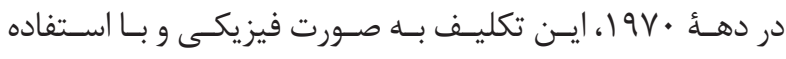

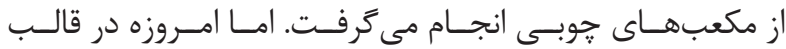

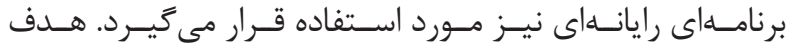

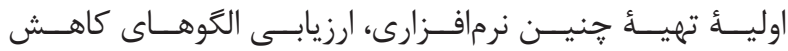

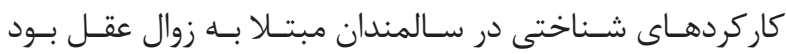

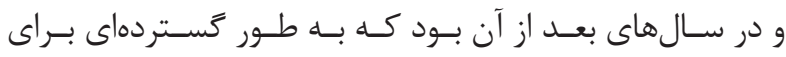

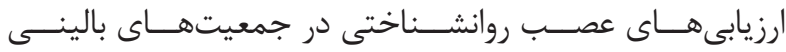

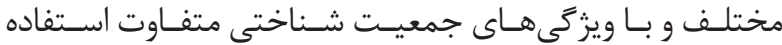

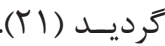

تجزيه و تحليل دادهها

روش آمارى

بـــراى بررسـى حافظــــ كارى ديــدارى -فضايــى در ايــن

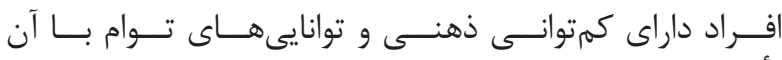

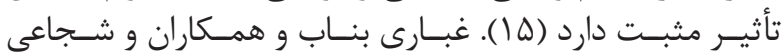

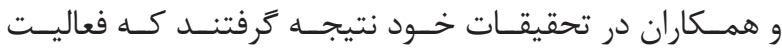

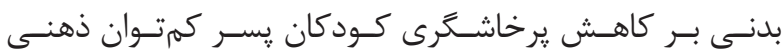

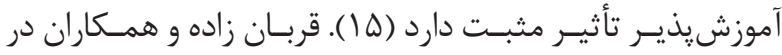

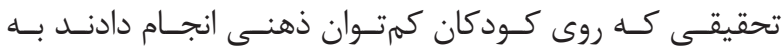

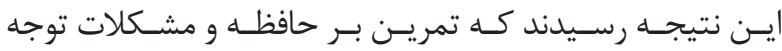

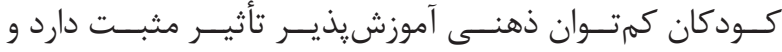

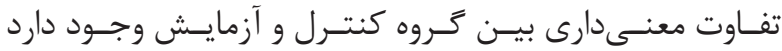

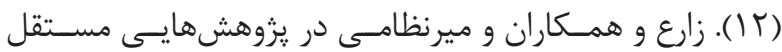

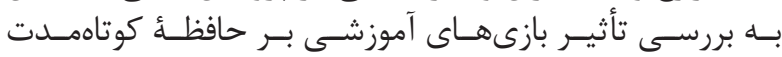

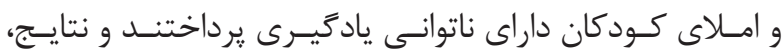

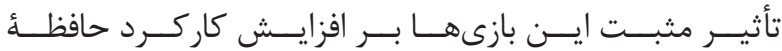

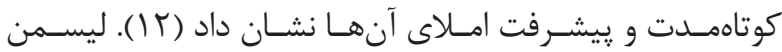

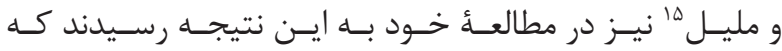

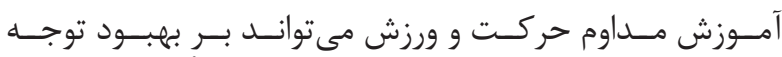

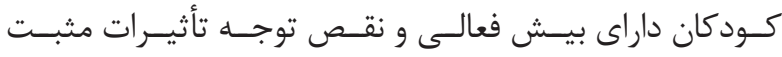

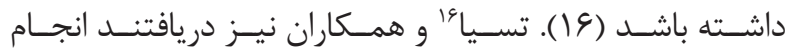

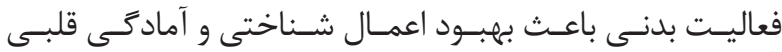

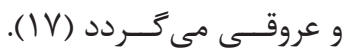

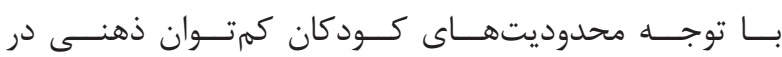

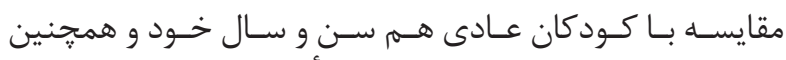

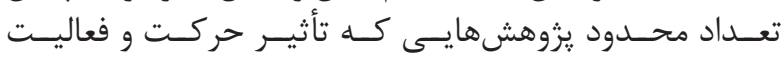

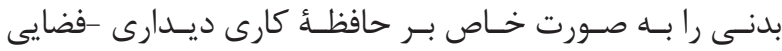

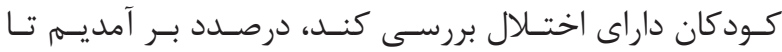

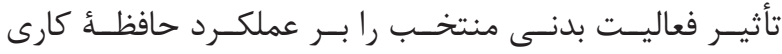

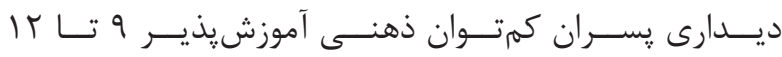
سـال را مـورد بررسـى قــرار دهيسمه. ذهن.

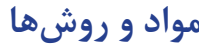

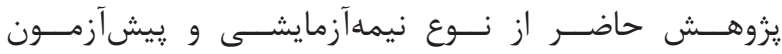

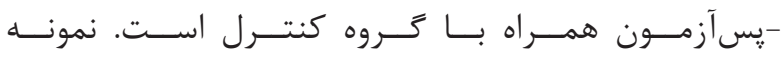

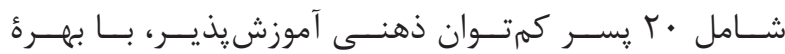

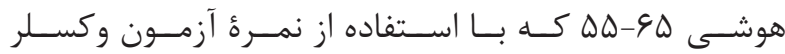

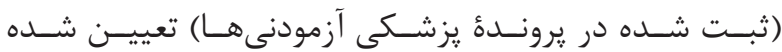

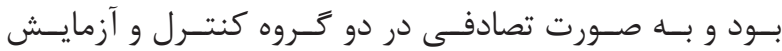

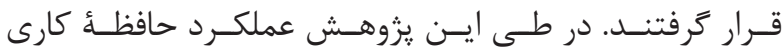

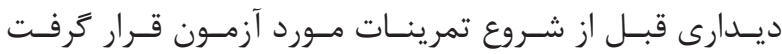

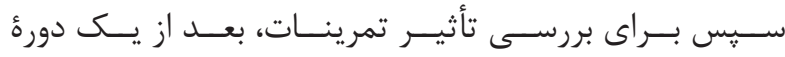

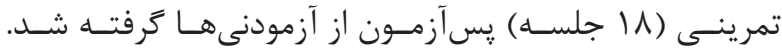

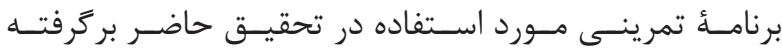

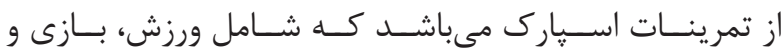

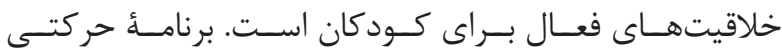

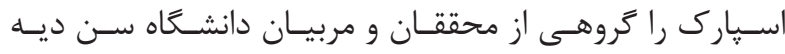

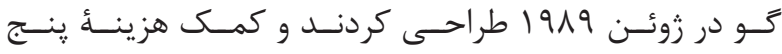

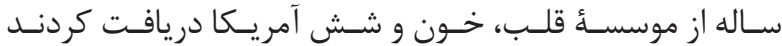

${ }^{15}$ Leisman and Melillo

${ }^{16}$ Tsia

${ }^{17}$ Corsi blocks task 


\begin{tabular}{|c|c|c|c|c|c|c|}
\hline & & & & & & \\
\hline فعاليتهاى تركيبى & همزمان و طرح هركت همثن & شناسايى بدنى & مهارتهاى جابجايى و & بينايى، شنيدارى و واكى فضى ادرانى & تعادل ايستاو يويا & جلسؤ \\
\hline كرور تمرينات & 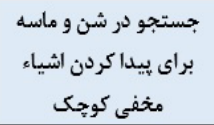 & جهش روى باى برتر & مجحاله كردن كاغذهاى & تخته و بيان جهت اشكال روى آن & مستركت روى خطيم به عقب و & جلسهُ \\
\hline باز و بسته كردن & تقليد راه رفتن حيوانات & 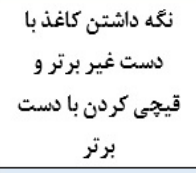 & 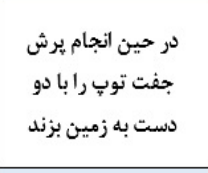 & كه از قبل جاى ياى جربت & يرش جفت درون & 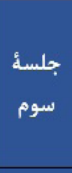 \\
\hline مرور تمرينات & ضربه به بادكنك در فضا & كامل كردن يازل بدن & حركت يروانه زدن & 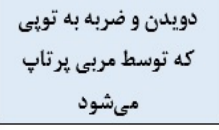 & ايستادن روى تختهُ & جهارم \\
\hline ساختن اشكال با & اشكال با زحشمان بسته & فرود لى لى با ياى برتر و هيا (بازى & ضربه با بشت بـ وروى & عبور به حالت زيكزَاق از & با جشتادان روى يسته يا & جنجم \\
\hline مرور تمرينات & نوك بينى رالمس كردم بسته & ترسيم بدن انسان و & انداختن توب به داخل & تعقيب توب آونكى با & نرم به حالت يك يا & جمأ \\
\hline ساختن اشكال با & برترون منطقة مشَّة لاستيكى به & 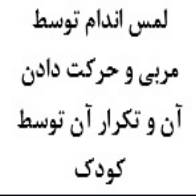 & يرش جفت از روى مانع & 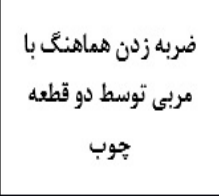 & راه رفتن روى تخته & جلسئ \\
\hline مرور تمرينات & تقليد حركت مربى ايستان روى تيوب & عبور از يهلو از درون & عبور از داخل حلقه & كاغذ كاغد اشكال روى & ايستادن روى تيوب & هلسئ \\
\hline مرور تمرينات & زمشن توب به منطقة & بخش فراى مخترتن عملكرد بدن & 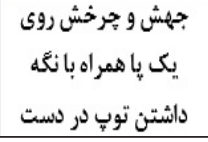 & يرتاب توب به مناطق & جرش و جرخش يا & جلهم \\
\hline
\end{tabular}

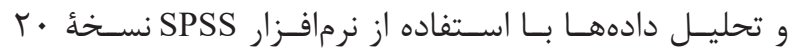
و در سـطح اطمينــان هـ • • انجــام شــد.

يافتهها

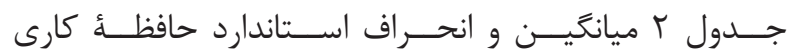

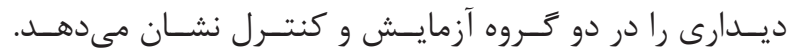

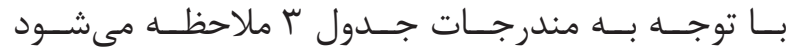

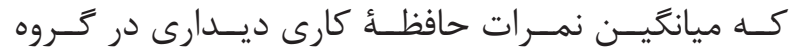

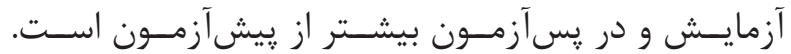

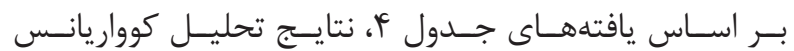

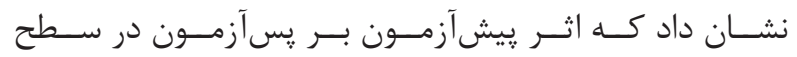

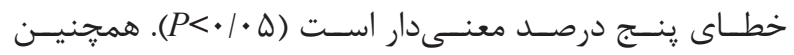

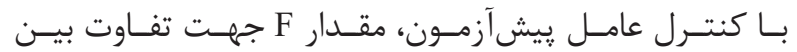

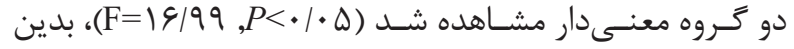

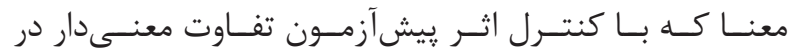

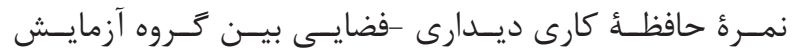

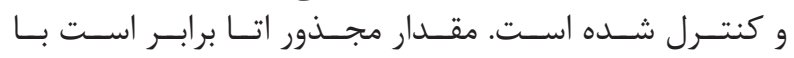

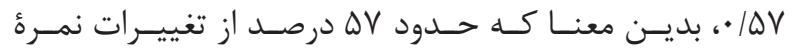

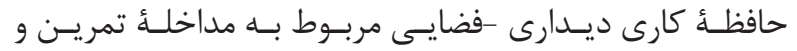

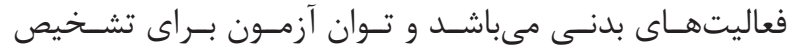

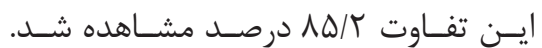

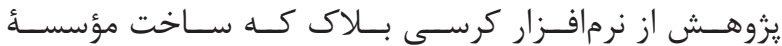

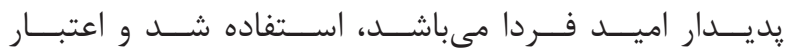

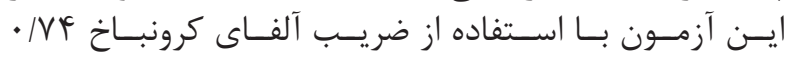

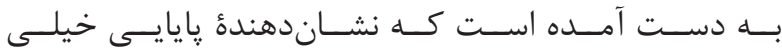

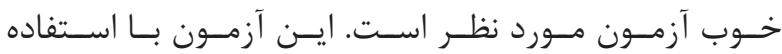

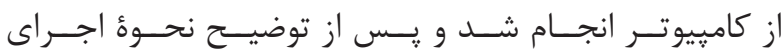

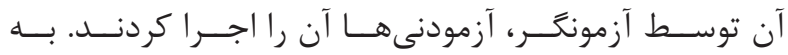

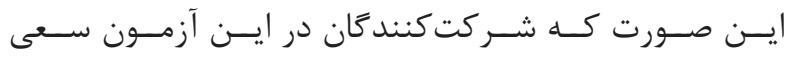

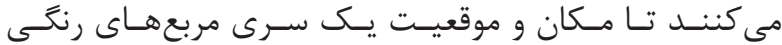

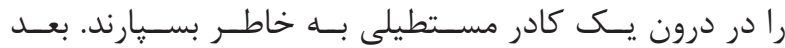

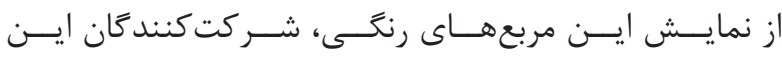

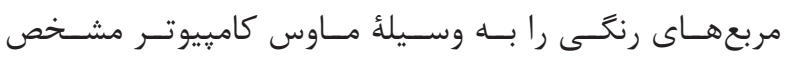

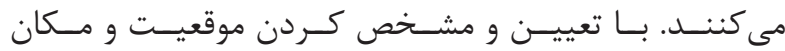

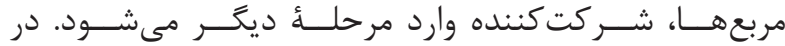

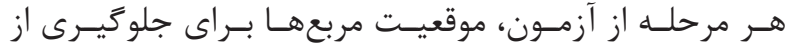

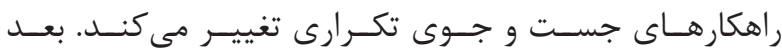

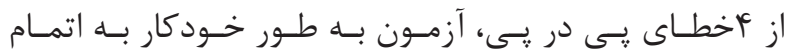

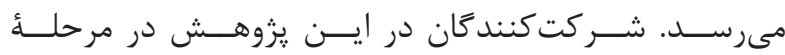

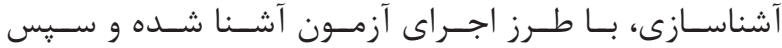

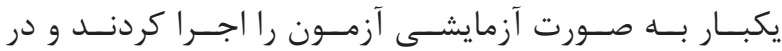

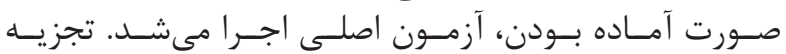


جدول r- شاخصهاى توصيفى دو كروه كنترل و آزمايش.

\begin{tabular}{|c|c|c|c|c|}
\hline وزن (كيلوَرم) & قد (سانتىمتر) & سن (سال) & \multirow{2}{*}{ تعداد } & \multirow{2}{*}{ تروه } \\
\hline انحراف土 ميانگين & انحراف土 ميانگين & انحراف土 ميانگين & & \\
\hline$r q / \Delta \pm \cdots / 19$ & $|r \cdot| \Delta \pm \varepsilon \cdot \mid \Lambda \cdot$ & $1 \cdot \mid 1 \pm 9 / 4$ & 1 . & كنترل \\
\hline$r \cdot 10 \pm \cdot \cdot 119$ & $119 / \Delta \pm \Delta \Delta / 9$. & $1 \cdot / 1 \pm V / 9$ & $1 \cdot$ & آزمايش \\
\hline
\end{tabular}

\begin{tabular}{|c|c|c|c|c|c|c|}
\hline انحراف استاندارد & ميانگين & بيشينه & كمينه & ت تعداد & كروه - ت كره & متغير \\
\hline .1 .9 & $r / T \Delta$ & $\Delta$ & r & 1. & ي يِشآزمون & \multirow{4}{*}{ ديدارى -فضائ كارى } \\
\hline$\cdot / \cdot V$ & $r / v \Delta$ & \& & r & 1. & ֶِآزمون & \\
\hline . $/ \Delta T$ & r/9 & i & $r$ & 1. & يِيشآزمون & \\
\hline .190 & $r / 1$ & f & r & 1. & يسآزمون & \\
\hline
\end{tabular}

جدول F- نتايج آزمون تحليل كوواريانس يكطرفه در مرحلة بِسآزمون بين كروهها.

\begin{tabular}{|c|c|c|c|c|c|c|}
\hline ميزان تأثير & معنى دارى & F & ميانگين مجذورات & درجئة آزادى & مجموع مجذورات & متغير \\
\hline.$|\Delta\rangle$ & .1 .19 & $18 / 99$ & $11 / \mathrm{V}$ & 1 & $11 / \mathrm{V}$ & كرووها \\
\hline
\end{tabular}

فعاليتهـاى حركتـى فــرد دسـتخوش تغييــر مىشــود (I (I).

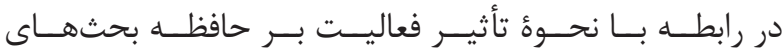

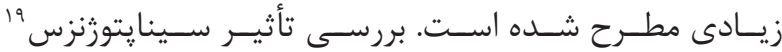

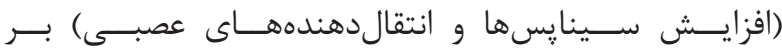

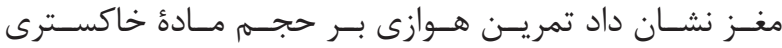

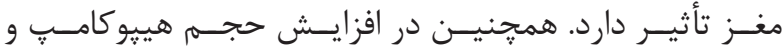

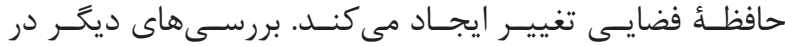

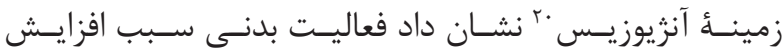

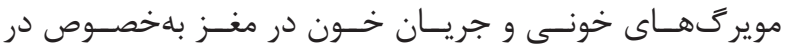

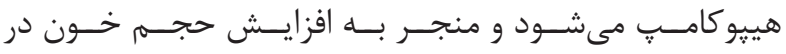

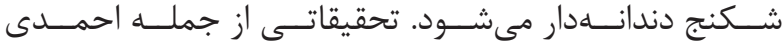

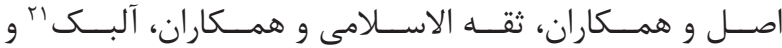

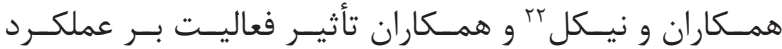
شــاختى، ياد

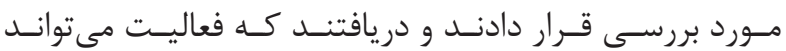

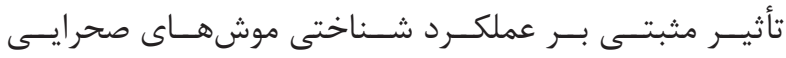

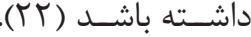

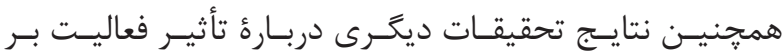

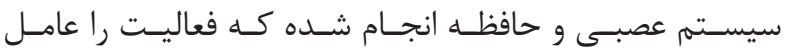

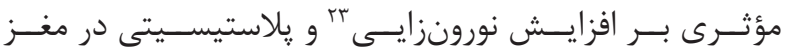

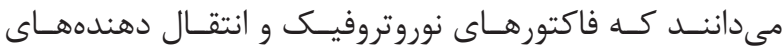

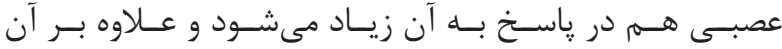

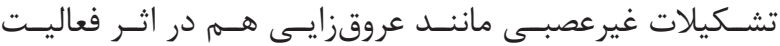

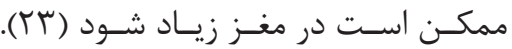

${ }^{18}$ Piaget

${ }^{19}$ Synaptogenesis

${ }^{20}$ Angiosis
بحث و نتيجهَيرى

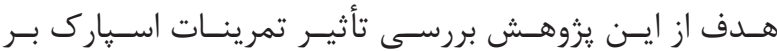

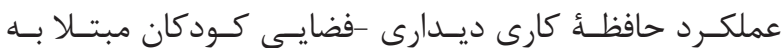

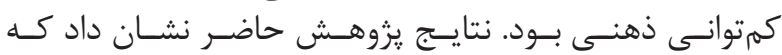

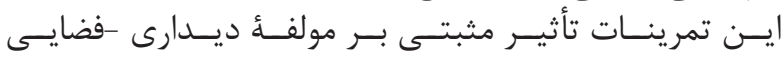

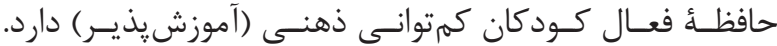

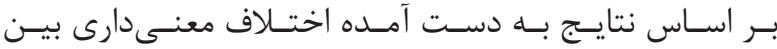

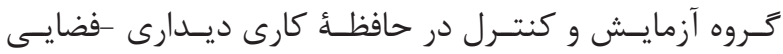

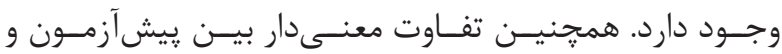

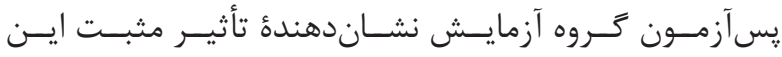

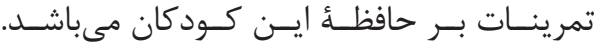

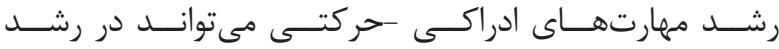

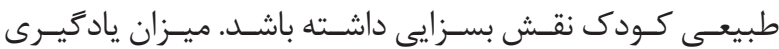

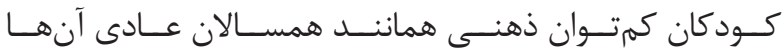

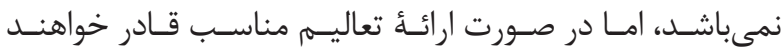

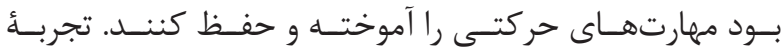

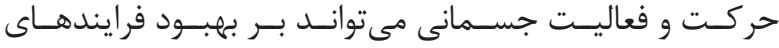

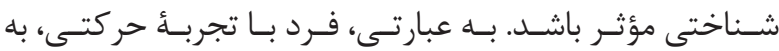

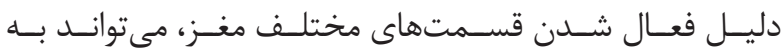

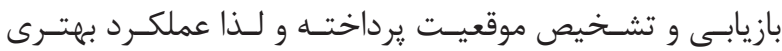

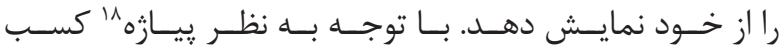

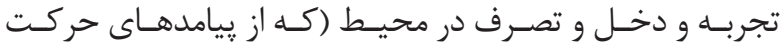

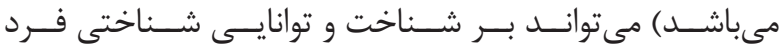

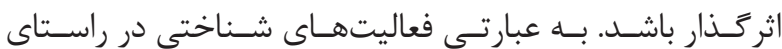
${ }^{21}$ Albeck
${ }^{22}$ Nichol
${ }^{23}$ Neurogenesis 


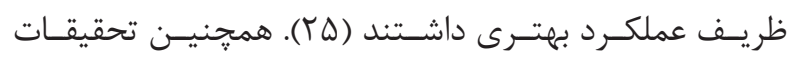

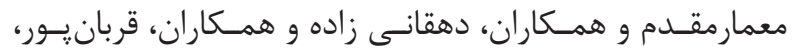

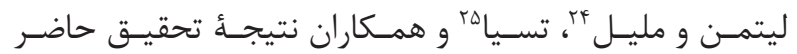

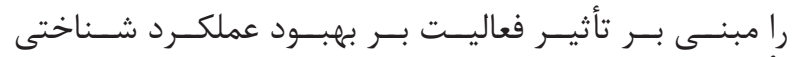

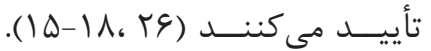

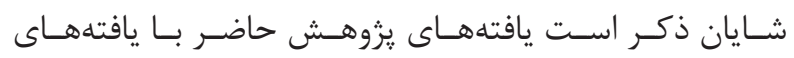

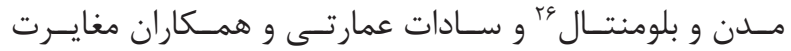

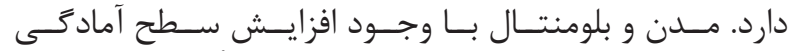

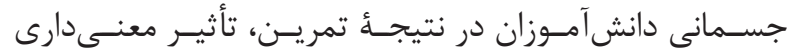

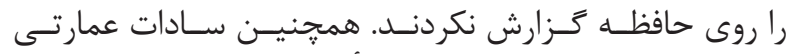

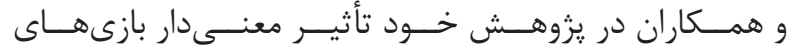

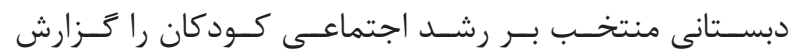

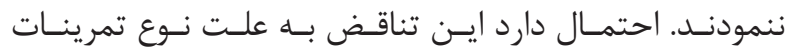

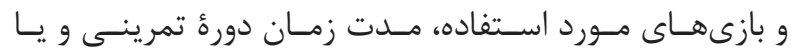

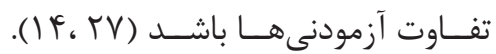

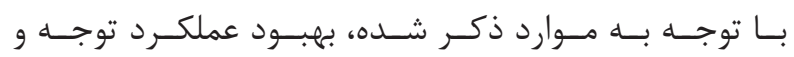

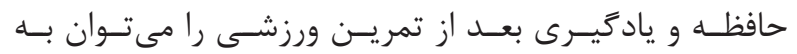

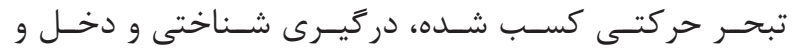

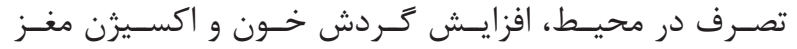

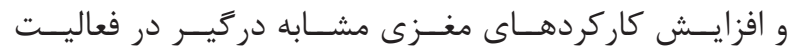

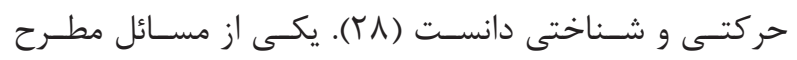

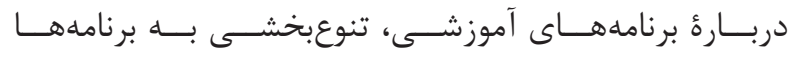

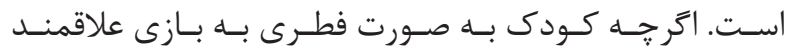

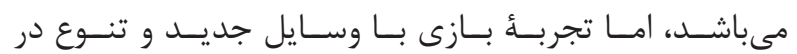

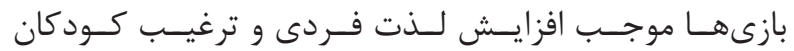

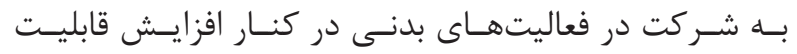

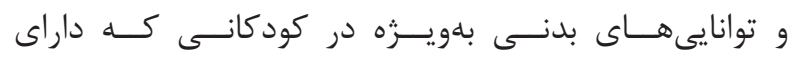

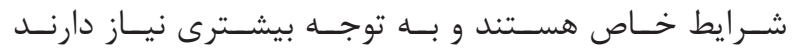
مى شـــود.

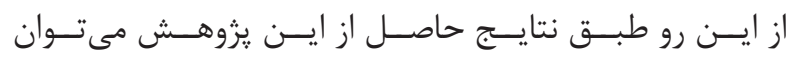

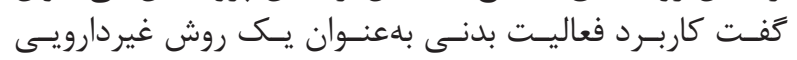

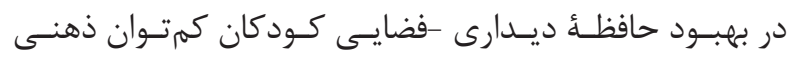

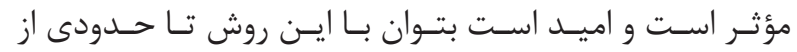

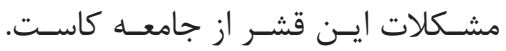

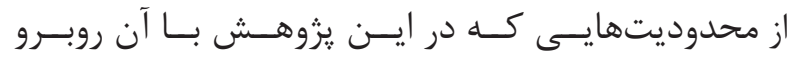

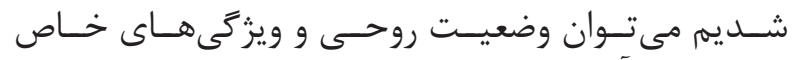

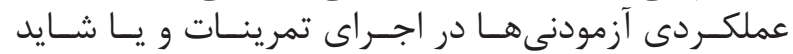

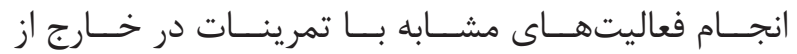

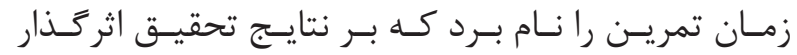
بـوده اسـت تمكن تشكر و قدردانى

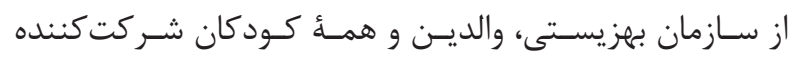

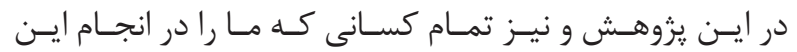

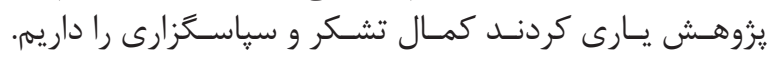

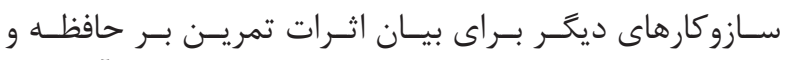

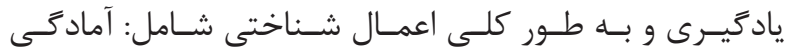

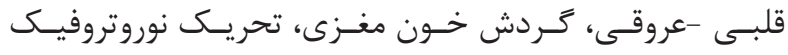

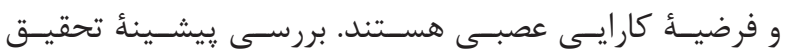

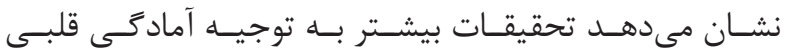

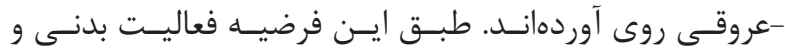

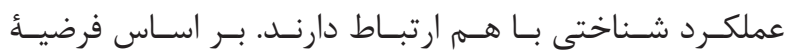

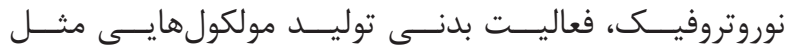

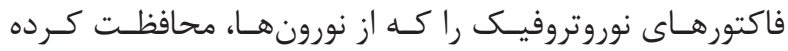

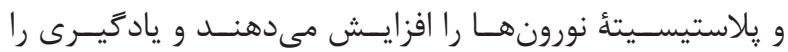

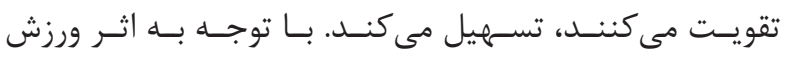

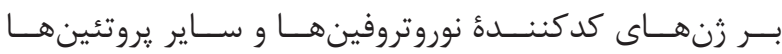

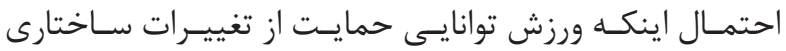

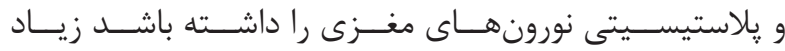

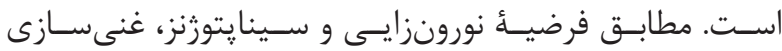

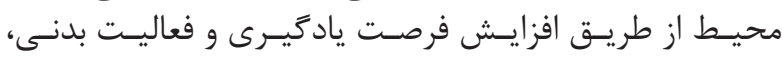

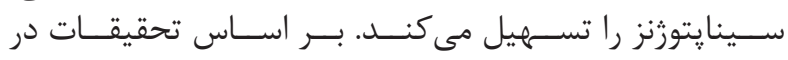

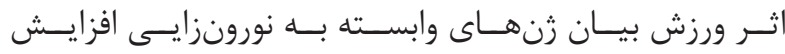

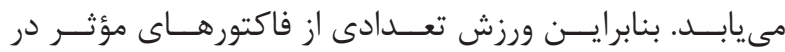

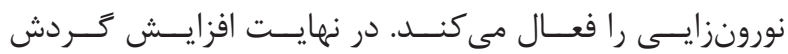

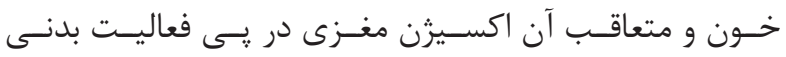

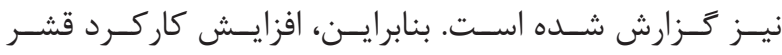

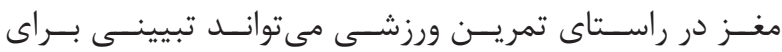

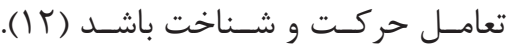

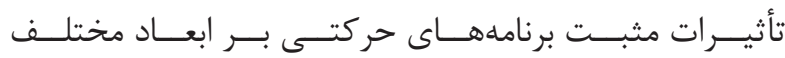

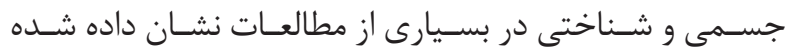

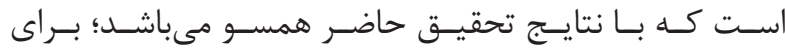

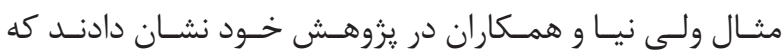

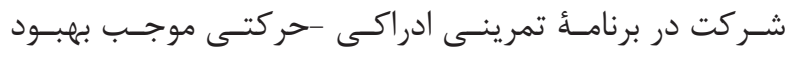

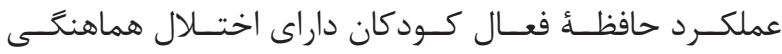

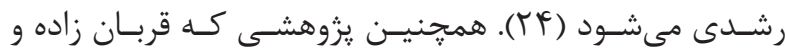

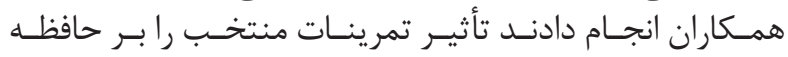

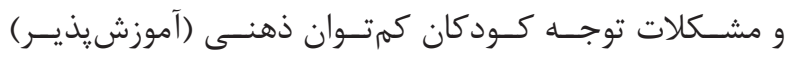

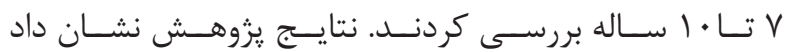

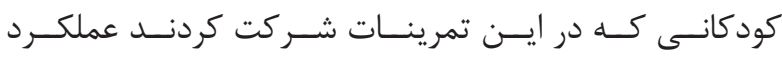

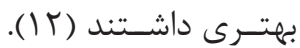

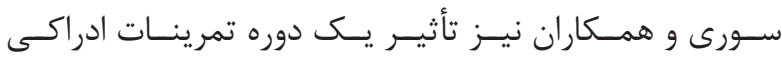

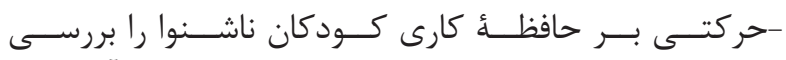

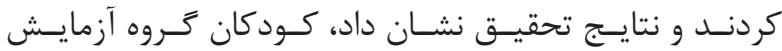

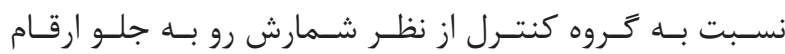

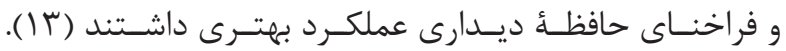

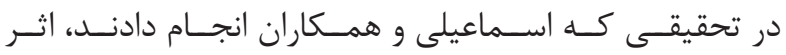

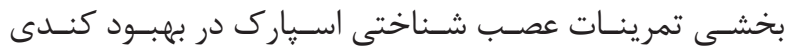

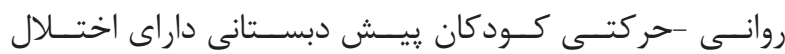

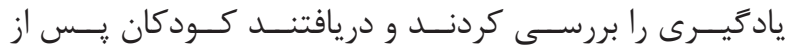

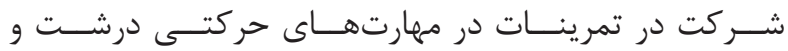

\footnotetext{
${ }^{24}$ Lithman and Melil

${ }^{25}$ Tesia

${ }^{26}$ Meden and Blomental
} 
1. Afruz G. Psychology and rehabilitation of children slowly (mentally retarded). $12^{\text {nd }}$ ed. Tehran; Tehran University Press. 2015; p. 93-112.

2. Awh E, Jonides J. Overlapping mechanisms of attention and spatial working memory. J Cognitive Sciences. 2001; 5(3): 119-26.

3.Moshirian Farahi SM. Zarif Golbar Yazdi H, Amin Yazdi SA. Investigate visual-spatial attention and visual-manual dexterity skills in children with learning disorders and compare with normal children. J Psychol Cogn. 2016; 4(3): 25-34.

4. Colcombe SJ, Erickson KI, Raz N. Aerobic fitness reduces brain tissue loss in aging humans. J Gerontol a BiolSci Med Sci. 2003; 58(2): 176-80.

5. Lo Bue-Estes C, Willer B, Burton H, Leddy JJ, Wilding GE, Horvath PJ. Shortterm exercise to exhaustion and its effects on cognitive function in young women. Percept Mot Skills. 2008; 107(3): 933-45.

6. Brutvan JJ. The effect of exercise on cognitive function as measured by impact protocol: aerobic vs. anaerobic. Kent State University. Master's Thesis. 2011; p: $23-27$.

7. Galahu DL, Ozmun JC. Understanding motor development. Hemayattalab R, Movahedi A. Farsi A, Fuladian J. Tehran. Science and Motion Pub. 2006; 40327.

8. Fazel Kalkhoran J, Shariati A, Bahrami H. Effect of play therapy on the short-term memory disability educable children. J Motor Behav. 2017; 9(28): 73-88

9.Khodaparast Z. Investigating the effectiveness of game therapy on visual memory and focusing and attention of educable mentally retarded students. Exceptional Education. 2014; 7(128): 21-9.

10. Hardman ML, Drew CJ, Winston Egan M. Psychology and education exceptional children. $3^{\text {rd }}$ ed. Tehran: Danjeh. 2011: p. 288-9.

11. Cooper R, Kuh D, Cooper C, Gale CR, Lawlor DA, Matthews F, et al. Objective measures of physical capability and subsequent health: a systematic review. Age Ageing. 2011; 40(1): 14-23.

12. Ghorbanzadeh B, Lotfi M. Effect of selected perceptual-motor practices on memory and attention problems in children with intellectual disability. Sports Psychology Studies. 2015; 14: 45-58.
منابع

13. Souri Z, Heirani A, Rafiee F, Falahi Z. Effect of eightweek perceived-movement exercises on deaf children's working memory. Journal of Motor Learning and Development. 2017; 9(2): 319-33.

14. Meemarmoghadam M. Taheri H. Sohrabi M. Mashhadi A. Kashi A. The effect of a selected exercise schedule on the work memory of children with attention deficit / hyperactivity disorder (ADHD). J Motor Behav. 2015; 22(1): 149-62.

15. Dehghanizadeh J, Lotfi $M$, Mohammadzadeh $H$. The effect of workout and exercise exercises on mental rotation. Journal of Motor Learning and Development. 2016; 8(3): 113-25.

16 .Leisman G. Melillo R. Effects of motor sequence training on attentional performance in ADHD children. Int J Disabil Hum Dev. 2010; 9(4): 275-82.

17. Tsai CL, Chen FC, Pan CY, Wang CH, Huang TH, Chen TC. Impact of acute aerobic exercise and cardiorespiratory fitness on visuospatial attention performance andserum BDNF levels. Psychoneuroendocrinology. 2014; 41: 121-31.

18. Akbari H. Comparison of spark's motion program with growth-based gymnastics training program on the development of stem skills in children 6 to 8 years old. Journal of Motor Learning and Development. 2012; 13: $103-18$.

19 .Kosari S. The effect of selected physical activity on the development of motor skills in children with a disorder attention deficit / hyperactivity disorder(ADHD). Master's Thesis. University of Tehran. 2010.

20. Aghababaei S, Amiri Sh. Visual-spatial component of working memory and short-term memory in students with learning disorders and in normal students. J Psychology. 2015; 2(4): 1-9.

21. Moshirian Farahi SM, Zarif Golbar Yazdi H. Amin Yazdi SA. Investigate visual-spatial attention and visualmanual dexterity skills in children with learning disorders and compare with normal children. Journal of Cognitive Psychology. 2016; 4(3): 25-35.

22. Seghatoleslami A, Shaikh M, Naghdi N, Arabameri E, Namvar Asl N. The effect of running on treadmill in learning of male rat. Journal of Motor Learning and Development. 2012; 11(1): 115-38.

23. Irandust KH, Tahery M, Sadeghi A. The effect of exercise (swimming and running) on motor function, 
learning and spatial memory in elder male wistar rats. Journal of Motor Learning and Development. 2014; 6(2): 259-70.

24. Valinia Z, Heirani A, Yazdanbakhsh K. Effect of eight-week perceived-movement exercises on children's work memory with developmental coordination disorder. Journal of Rehabilitation Medicine. 2017; 6(3): 211-20.

25. Esmaeili S, MovahediY, Rostami S, Esmaeili S. Effectiveness of physical neurological exercise on the growth of the psychomotor skills in children with learning disorder. Journal of Recognition Psychology and Psychiatry. 2015; 2(3): 16-28.
26. Ghorbanpour K, Pakdaman M, Rahmani MB, Gholamhosseini H. The effect of rhythmic movement and playing aerobic on short-term memory functionand auditory memory of students with learning disabilities. (Journal of Health Breeze) Family Health. 2013; 1(4): 35-44.

27. Gholami A, Abani Arani M, Ghasemi A, Ghafari B. The effect of selected rainbow parachute games on motor and social development of pre-school children. J Motor Behav. 2016; 8(24): 189-204.

28 .Dehghani Zade J, Mohammad Zadeh H, Hosseini FS. The effect of gymnastic program on mental rotation. Journal of Cognitive Psychology. 2013; 1(1): 16-24. 